\title{
Evaluating the Efficacy of Two Decalcifying Agents on Hard and Soft Tissues of Human Permanent Teeth
}

\author{
Sheeba Ali1 ${ }^{1}$, Puja Bansal², Deepak Bhargava ${ }^{3}$, Ashish Choudhary 4 , Anurag Hasti ${ }^{5}$, \\ Vidyadevi Chandravarkar6, Mithilesh Mishra ${ }^{7}$, Shafali Singh ${ }^{8}$
}

1,2,3,6,7,8 Department of Oral Pathology \& Microbiology, School of Dental Sciences, Sharda

University, Greater Noida, Uttar Pradesh, India, 4,5 Department of Prosthodontics and Crown \&

Bridge, School of Dental Sciences, Sharda University, Greater Noida, Uttar Pradesh, India.

\section{ABSTRACT}

\section{BACKGROUND}

Human teeth and bones consist of hard and soft tissues. Preparing calcified tissues for histological analysis by decalcification is a time-consuming procedure, and the quality of the sections thus obtained is dependent on the speed with which decalcification occurs, as well as the chemistry of the decalcification agent. The present study was intended to identify the method that combines the highest quality of stained sections with a short period of time.

\section{METHODS}

50 extracted premolars were subjected to decalcification using $10 \%$ Formic acid and $5 \%$ Trichloroacetic acid (TCA). The efficacy of decalcifying agents was evaluated by recording the time taken by particular acid to decalcify the tooth completely. The preservation of morphological characteristics was assessed on the basis of ease of sectioning, uniformity of staining, damage to odontoblast layer, retraction of pulp and fraying of dentinal tubules.

\section{RESULTS}

Comparatively decalcification was faster with $5 \%$ TCA than $10 \%$ Formic acid. Whereas, $10 \%$ formic acid was more considerate on soft tissues than $5 \%$ TCA. All the results were statistically significant.

\section{CONCLUSIONS}

Samples decalcified with $10 \%$ formic acid gave fairly good results, so it can be used in cases of diagnostic urgencies.

\section{KEY WORDS}

Teeth, Decalcification, Acids, Histopathology
Corresponding Author: Dr. Sheeba Ali,

Assistant Professor Department of Oral Pathology \& Microbiology, School of Dental Sciences, Sharda University, Greater Noida, Uttar Pradesh, India. E-mail: dr.sheebaali@gmail.com

DOI: 10.14260/jemds/2021/491

How to Cite This Article:

Ali $S$, Bansal $P$, Bhargava $D$, et al. Evaluating the efficacy of two decalcifying agents on hard and soft tissues of human permanent teeth. J Evolution Med Dent Sci 2021;10(31):2396-2400, DOI: 10.14260/jemds/2021/491

Submission 20-03-2021, Peer Review 30-05-2021, Acceptance 07-06-2021, Published 02-08-2021.

Copyright (c) 2021 Sheeba Ali et al. This is an open access article distributed under Creative Commons Attribution License [Attribution 4.0 International (CC BY 4.0)] 


\section{BACKGROUND}

Demineralization is a rapidly growing and challenging aspect of various scientific disciplines like astrobiology, paleoclimatology, geomedicine, archaeology, geobiology, dentistry, histology, biotechnology, and many others. ${ }^{1}$ Composition of enamel, dentin and cementum together with highly mineralized extracellular matrix makes teeth as hardest tissues in the body. ${ }^{2}$ For understanding cellular and subcellular structures and functions, its necessary to preserve the hard tissues close to living state. In recent times, through plastic processing techniques it is possible to make histological preparations from undecalcified teeth. They give good results in terms of eliminating shrinkage and for demonstrating osteoid versus mineralized matrix but gives poor cytological details. ${ }^{3}$ Moreover, these techniques require laboratories with highly specialized equipment, qualified personnel, advanced facilities, and safety standards. Therefore, these techniques cannot be performed routinely. 4,5

The most common method for obtaining sections from hard tissues for histological examination is to soften them by decalcification, a procedure in which acids or chelating agents are used to remove calcium salts from mineralized tissues, while preserving the organic portions. ${ }^{6}$ Decalcification is a dissolution process taking place at conditions in which the calcium phosphate phases are undersaturated with regard to the respective fluid with which they are in contact. ${ }^{1}$ In the histopathology laboratory hard tissue decalcification is one of the most technique sensitive procedures and in oral pathology laboratory it is of more significance as decalcification of bone and teeth is routinely carried out. ${ }^{7}$

The decalcifying agents should have an acidic action in order to remove and turn the calcium salts, which are insoluble in the tissues, into soluble salts. ${ }^{8}$ Chelating agents like Ethylene diaminetetraacetic acid (EDTA) and weak organic acids like formic acid and TCA are comparatively slow in their action but carry low risk of tissue damage as compared to strong acids like nitric acid which are capable of causing protein hydrolysis which may lead to dissolution and maceration of soft tissues. ${ }^{9}$ The choice of decalcifying agent is greatly influenced by urgency of the case, degree of mineralization, extent of investigation and staining techniques required. ${ }^{10}$ Therefore, an ideal decalcifier should ensure that crystals have been removed completely from specimen, minimum damage to cells and tissues has been done, there is non-impairment to subsequent staining and the speed of decalcification is at reasonable rate. 6 Many studies have been done to understand the interaction of acids with hard and soft tissues of bone and teeth but exact inherent mechanism is still not understood. Hypothetically, it is considered that pKa value of the acid generally determines decalcification process of apatite crystals. ${ }^{11}$

Pathologist's main concern is to reduce the time between receiving a specimen and reporting the diagnosis. For this purpose, various methods have been used during the years to hasten histoprocessing including frozen section, rapid manual tissue processing, and heating which have considerable shortcomings. ${ }^{12}$ There is a constant demand on the development of better techniques to perform quick, safe, repeatable, and easy investigations of hard tissue's extracellular matrix, cells, or intracellular structures. ${ }^{5}$

In the present in-vitro study we compared the efficacy of $10 \%$ Formic acid and $5 \%$ Trichloroacetic acid (TCA) in human permanent teeth including a qualitative analysis of tissue preservation, thereby determining more effectiveness of decalcifying agent.

\section{METHODS}

Ethical clearance from internal research committee of the institute was obtained. An in-vitro study was carried out in Sharda University, School of Dental Sciences, Department of Oral Pathology, Greater Noida. Patients were verbally informed and after taking written consent a qualitative study was carried out from August 2013 to September 2014.

Sample included a total of 50 freshly extracted premolars. 25 teeth were designated for $10 \%$ Formic acid and 25 teeth for $5 \%$ trichloroacetic acid (TCA). Carious teeth, teeth with attrition, erosion or abrasion and fluorosis were excluded from the study.

After receiving teeth in $10 \%$ formalin, they were washed under running tap water for 2 - 3 minutes to clean any debris or blood clots, after which they were again placed in fresh 10 $\%$ neutral buffered formalin for both preservation and fixation for minimum period of $24 \mathrm{hrs}$. Each tooth sample was assigned with a particular number.

\section{Method of Decalcification}

Decalcification was carried out by completely suspending a tooth sample in a glass beaker containing $100 \mathrm{ml}$ of decalcifying agent (Figure 1(i)). Starting date and time of decalcification were recorded for each tooth. Procedure was carried out at room temperature. Daily agitation of the solution with glass stirrer was done. End point of decalcification was checked routinely.

All the decalcified teeth specimens (Figure 1(ii)) were washed under running tap water for 2 - 4 hours. They were then kept for routine tissue processing and staining. Time taken by tooth for complete decalcification was noted down. Ease of sectioning of specimens was evaluated while cutting of sections by microtome. The $\mathrm{H} \& \mathrm{E}$ stained decalcified sections were observed under the microscope and evaluated for damage to odontoblast layer, retraction of pulp, fraying of dentinal tubules and patchy staining. These parameters were evaluated as present and absent.

\section{Statistical Analysis}

Results were calculated as Mean \pm SD for time taken for complete decalcification. For analysing data of ease of sectioning, damage to odontoblast layer, fraying of dentinal tubules, retraction of pulp and patchy staining, chi-square test was applied and $\mathrm{P}$ - value $<=0.05$ was considered for statistical significance. 


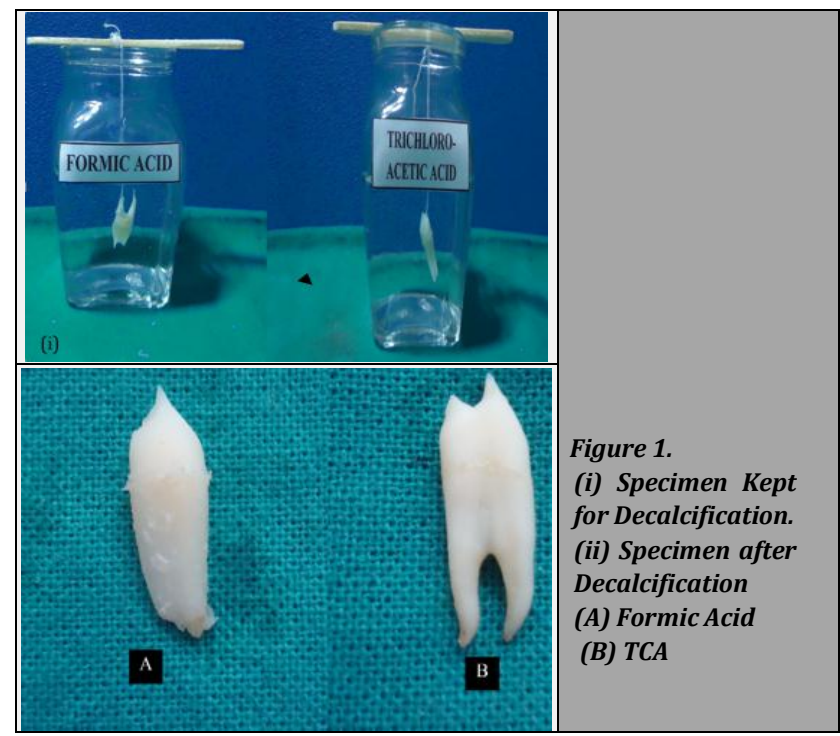

RESULTS

Comparatively $10 \%$ formic acid was slower than $5 \%$ TCA in decalcifying a single tooth completely (Table 1). Samples decalcified by $10 \%$ formic acid were easier to section by microtome, less friable and easy to handle than $5 \%$ TCA. (Table 1). All the results obtained were statistically significant.

Damage to odontoblast layer, retraction of pulp and fraying of dentinal tubules were less in samples decalcified by $10 \%$ EDTA (Figure 3) relatively $5 \%$ TCA showed more damage to odontoblast layer, retraction of pulp and fraying of dentinal tubules (Figure 4, Table 2). Formic acid decalcified samples showed good staining results, whereas, patchy staining was seen in many samples decalcified by $5 \%$ TCA. (Table 2, Figure 4). All the results obtained were statistically significant.

\begin{tabular}{|cccccc|}
\hline Acids & $\begin{array}{c}\text { Time Taken (Days) } \\
\text { for Complete } \\
\text { Decalcification }\end{array}$ & \multicolumn{3}{c|}{$\begin{array}{c}\text { Parameters } \\
\text { Ease of Sectioning }\end{array}$} \\
& Mean & SD & $\begin{array}{c}\text { Easy } \\
{[\mathrm{N}(\%)]}\end{array}$ & $\begin{array}{c}\text { Difficult } \\
{[\mathrm{N}(\%)]}\end{array}$ & Total (N) \\
\hline Formic acid & 12.20 & \pm 2.29 & $14(56 \%)$ & $11(44 \%)$ & 25 \\
Trichloroacetic acid \\
Chi square statistic
\end{tabular}

\section{DISCUSSION}

In humans, head and neck is a complex structure of both hard and soft tissues. ${ }^{6}$ To obtain histological sections from hard tissues, commonly used method is to soften them by demineralization. The most usual technique of decalcification is to subject the hard tissue to the action of acids. Alternatively, chelating agents are used to sequester the calcium and leave the organic matter as a residue. Most modern treatises on histology describe in detail the various modifications of these two basic methods. ${ }^{13}$ The urgency of procedure dictates the choice of decalcifying agent used. Information pertaining to the relation of soft tissue to a tooth, involvement of bone by tumour, resorption pattern and remodelling of bone etc. decide the optimal management of the lesion. ${ }^{14}$

For removing calcium from the centre of large specimens it has to remain in contact with decalcifying solution for longer duration, because of which distortion of superficial layer of specimen may occur. This may lead to reduced stability and affects the staining quality of the tissues. ${ }^{15}$ therefore, a right balance between speed and quality of staining has to be there for timely diagnosis. Researchers have been trying to introduce new decalcifying agents or modify presently used agents, so that the criteria of the most efficient decalcifying agent which ensures complete removal of calcium from specimen without causing damage to tissue architecture and provides adequate staining characteristics. ${ }^{16}$ In our study an attempt has been made to evaluate the efficacy of two decalcifying agents in human permanent teeth. In our study, decalcification was little slow by $10 \%$ formic acid $12.20 \pm 1.5$ days as compared to $5 \%$ trichloroacetic acid which took around $10.60 \pm 2.29$ days to completely decalcify a single permanent premolar. (Table1) Singh S, et al. ${ }^{17}$ concluded that the time taken by $10 \%$ formic acid to completely decalcify a tooth was approximately 7 - 9 days. Bancroft also found that around 1 - 10 days were required for decalcification using formic acid. ${ }^{10}$ But in our study, time taken by $10 \%$ formic acid was slightly more. Contrary to our findings Verdenius H. H. W, et al. ${ }^{18}$ found that at room temperature, the time required for complete decalcification by $10 \%$ trichloroacetic acid and $10 \%$ formic acid was 8 and 21 days, respectively. Srinivasyaiah et. al. ${ }^{19}$ also noted that the time taken by $7 \%$ formic acid and $5 \%$ TCA to decalcify a single tooth via conventional method was 40 and 39 days respectively.

The decalcification process is accelerated when the solution is shaken, mechanically or electrically. ${ }^{20}$ In our study, the decalcifying solution was agitated by using a glass stirrer. End point of decalcification should be determined accurately as under calcified tissues are very difficult to section, moreover distorted sections will be obtained. Conversely, if the decalcification time is unduly prolonged, both hard and soft tissues may be damaged. The methods commonly used for end point determination of decalcification are physical, chemical, and radiological.10,21 Although very expensive and not readily available in most histology laboratories, $\mathrm{X}$ - ray microcomputed tomography $(\mu \mathrm{CT})$ is the most accurate and precise method for quantifying mineral density. ${ }^{22}$ In our study, for end point determination of decalcification, we used both physical and chemical method.

\begin{tabular}{|c|c|c|c|c|c|c|c|c|c|c|c|c|}
\hline \multirow{3}{*}{ Acids } & \multicolumn{12}{|c|}{ Parameters } \\
\hline & \multicolumn{3}{|c|}{ Damage to Odontoblast Layer } & \multicolumn{3}{|c|}{ Retraction of Pulp } & \multicolumn{6}{|c|}{ Fraying of Dentinal Tubules Patchy Staining } \\
\hline & $\mathrm{P}[\mathrm{n}(\%)]$ & $\mathrm{A}[\mathrm{n}(\%)]$ & $\mathrm{T}(\mathrm{n})$ & $\mathrm{P}[\mathrm{n}(\%)]$ & $\mathrm{A}[\mathrm{n}(\%)]$ & $\mathrm{T}(\mathrm{n})$ & $\mathrm{P}[\mathrm{n}(\%)]$ & $\mathrm{A}[\mathrm{n}(\%)]$ & $\mathrm{T}(\mathrm{n})$ & $\mathrm{P}[\mathrm{n}(\%)]$ & $\mathrm{A}[\mathrm{n}(\%)]$ & $\mathrm{T}(\mathrm{n})$ \\
\hline Formic Acid & $9(36 \%)$ & $16(64 \%)$ & 25 & $11(44 \%)$ & $14(56 \%)$ & 25 & $10(32 \%)$ & $15(68 \%)$ & 25 & $11(44 \%)$ & $14(56 \%)$ & 25 \\
\hline Trichloroacetic acid & $16(64 \%)$ & $9(36 \%)$ & 25 & $18(72 \%)$ & $7(28 \%)$ & 25 & $15(60 \%)$ & $10(40 \%)$ & 25 & $15(60 \%)$ & $10(40 \%)$ & 25 \\
\hline Chi square statistic & \multicolumn{3}{|c|}{$\begin{array}{l}\text { Chi }- \text { square }=3.92 \\
\mathrm{P} \text { - value is. } 141\end{array}$} & \multicolumn{3}{|c|}{$\begin{array}{l}\text { Chi - square }=4.023 \\
\text { p - value is. } 134\end{array}$} & \multicolumn{3}{|c|}{$\begin{array}{l}\text { Chi - square }=5.19 \\
\text { p - value is. } 074\end{array}$} & \multicolumn{3}{|c|}{$\begin{array}{l}\text { Chi }- \text { square }=1.28 \\
p \text { - value is. } 257\end{array}$} \\
\hline
\end{tabular}



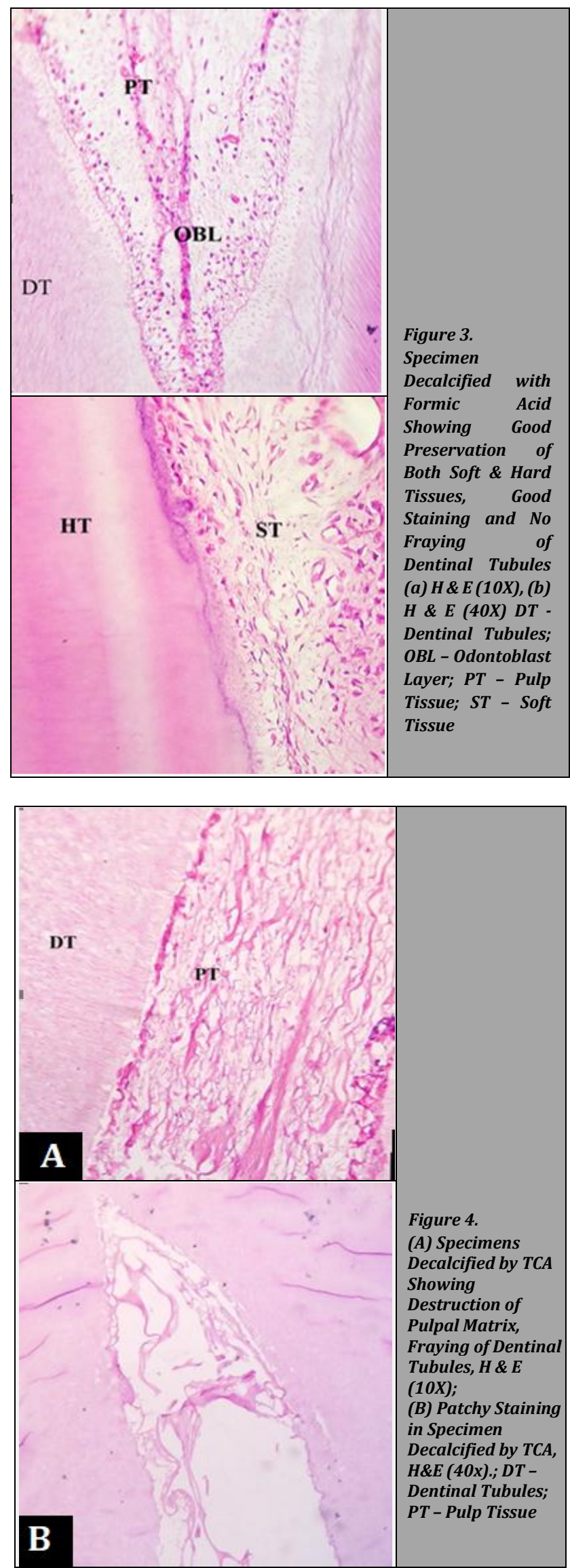

In our study we found that $56 \%$ specimens decalcified by formic acid were easy to section and easy to handle as compared to $5 \%$ trichloroacetic acid wherein only $48 \%$ specimens were easy to cut and were less friable. The results were statistically significant. (Table 1) Poor sectioning in case of $5 \%$ trichloroacetic acid could be attributed to the strong effect on the tissues which makes them friable and difficult to handle. ${ }^{10}$ The efficacy of the decalcifying agents was evaluated by observing damage to odontoblast layer, retraction of pulp from the dentinal wall, fraying of dentinal tubules and overall staining of the hard and soft tissue.

Formic acid showed $40 \%$ damage to odontoblast layer while trichloroacetic acid showed destruction in $64 \%$ cases and the results were statistically significant. Similar results were obtained by Sangeetha R, et al. ${ }^{9}$, Zappa J, et. al. ${ }^{4}$ (table 2, figure 3) $10 \%$ formic acid and $5 \%$ trichloroacetic acid showed retraction of pulp in $40 \%$ and $72 \%$ cases respectively (Table 2, Figure 3). Difference between the groups was statistically significant. Similar results were obtained by Prasad P, et al. ${ }^{23}$ Our study showed that fraying of dentinal tubules was maximum with trichloroacetic acid (60\% cases); while in formic acid, $40 \%$ cases showed fraying of dentinal tubules. The results were statistically significant. In a study, done by Prasad P, et al. ${ }^{23}$ maximum fraying was seen with formic acid. These results were contradictory to our study, as in our study TCA decalcified samples showed more fraying as compared to formic acid.

Selving KA found that dentinal tubules quickly open by the action of strong acids. These distorted tubules act as pathway for acids to reach the pulp tissue and thus destroying it. ${ }^{24}$ This could be the reason of maximum dentinal tubules fraying and distortion of pulpal architecture seen in many sections of specimens decalcified by TCA. Formic acid showed patchy staining in $44 \%$ of cases while trichloroacetic acid showed worst $\mathrm{H} \& \mathrm{E}$ staining with patchiness in $60 \%$ cases (Table 2, Figure 3). Similar results were obtained by Prasad P, et al. ${ }^{23}$ and Singh S, et al. ${ }^{17}$ On the contrary, Sanjai K, et al. ${ }^{6}$ Srinivasyaiah, et al. ${ }^{19}$ observed good staining characteristics with TCA but in our study, TCA showed poor H \& E staining in most of the cases. Staining properties are greatly affected by the acidity of the of the decalcifying solution and the time taken for complete decalcification. Lesser the time greater will be the injury to the tissues. Because of acid exposure, nucleus stains poorly with cationic dyes, such as haematoxylin, and cytoplasm overstained by the briefest exposure to anionic dyes such as eosin. 23

According to Athanasou NA, et al.25 TCA provided a rapid one step fixation and decalcification procedure that led to retention of many useful antigenic components, as well as excellent morphology and staining quality. This is contradictory to our findings since in our study, TCA showed poor morphology and staining quality. Contrary to our findings where formic acid showed less soft tissue shrinkage and loss of tissue, Zappa J, et al. ${ }^{4}$ found formic acid produced worst results in relation to soft tissue integrity. According to Gupta S, et al. ${ }^{16} 10 \%$ formic acid causes maximal damage to tooth tissues and hence should not be used for diagnostic purpose, while in our study $10 \%$ formic acid proved as an efficient decalcifier producing very less damage to the soft tissue structures, and results with $5 \%$ TCA were inferior as compared to formic acid.

In our study, damage to odontoblast layer, retraction of pulp, fraying of dentinal tubules and patchy staining was minimal by $10 \%$ formic acid. Extensive hard and soft tissue destruction was seen in case of $5 \%$ TCA. The overall difference in histological impression was statistically significant. We 
strongly recommend the use of $10 \%$ formic acid as routinely used decalcifying agent.

\section{CONCLUSIONS}

In histopathology, there is a constant tug of war between the rapidity of decalcification that is required against the quality of the sections that are needed. Significant alterations in soft tissues are provoked by strong acids like TCA. Therefore, many researchers have recommended that these should not be used for delicate tissues. Organic acids such as formic acid is better suited for soft tissues as they act slowly and require more time. According to many researchers' decalcification by using chelating agent like EDTA shows excellent results but its routine use becomes questionable because of time. $10 \%$ formic acid is the best all round decalcifier producing good histological results as well satisfying the time criteria.

Data sharing statement provided by the authors is available with the full text of this article at jemds.com.

Financial or other competing interests: None.

Disclosure forms provided by the authors are available with the full text of this article at jemds.com.

\section{REFERENCES}

[1] Ehrlich H, Koutsoukos PG, Demadis KD, et al. Principles of demineralization: modern strategies for the isolation of organic frameworks. Part I. Common definitions and history. Micron 2008;39(8):1062-91.

[2] Cho A, Suzuki S, Hatakeyama J, et al. A method for rapid demineralization of teeth and bones. Open Dent J 2010;4:223-9.

[3] Mawhinney WH, Richardson E, Malcolm AJ. Technical methods: control of rapid nitric acid decalcification. J Clin Pathol 1984;37(12):1409-15.

[4] Zappa J, Cieślik-Bielecka A, Adwent M, et al. Comparison of different decalcification methods to hard teeth tissues morphological analysis. Dent Med Probl 2005;42(1):21-6.

[5] Keklikoglu N, Akinci S. Comparison of three different techniques for histological tooth preparation. Folia Histochem Cytobiol 2013;51(4):286-91.

[6] Sanjai K, Kumarswamy J, Patil A, et al. Evaluation and comparison of decalcification agents on the human teeth. J Oral Maxillofac Pathol 2012;16(2):222-7.

[7] Kadashetti V, Shivakumar KM, Baad R, et al. A quantitative study of comparing the routine decalcification and microwave decalcification methods by using different decalcifying agents. Indian J Multidiscip Dent 2017;7(2):94-100.

[8] Mattuella LG, Bento LW, Vier-Pelisser FV, et al. Comparative analysis of two fixating and two decalcifying solutions for processing of human primary teeth with inactive dentin carious lesion. Rev Odonto Cienc 2007;22(56):99-105.

[9] Sangeetha R, Uma K, Chandavarkar V. Comparison of routine decalcification methods with microwave decalcification of bone and teeth. J Oral Maxillofac Pathol 2013;17(3):386-91.

[10] Callis GM. Bone. In: Bancroft JD, Gamble M, eds. Theory and practice of histological techniques. $6^{\text {th }}$ edn. Philadelphia: Churchill Livingstone 2008:333-63.

[11] Yoshida Y, Van Meerbeek B, Nakayama Y, et al. Adhesion and decalcification of hydroxyapatite by carboxylic acids. J Dent Res 2001;80(6):1565-9.

[12] Hajihoseini N, Rezvani G, Etemad-Moghadam S. Comparison of routine and microwave assisted decalcification of bone with or without teeth: a histologic study. Dent Res J (Isfahan) 2020;17(6):452-8.

[13] Cook SF, Ezra-Cohn HE. A comparison of methods for decalcifying bone. J Histochem 1962;67(4):560-3.

[14] Kapila SN, Natarajan S, Boaz K, et al. Driving the mineral out faster: simple modifications of the decalcification technique. J Clin Diagn Res 2015;9(9):ZC93-7.

[15] Fernandez MI, Gaio EJ, Kuchenbecker C, et al. Microscopic qualitative evaluation of fixation time and decalcification media in rat maxillary periodontium. Braz Oral Res 2007;21(2):134-9.

[16] Gupta S, Jawanda MK, Manjunath SM, et al. Qualitative histological evaluation of hard and soft tissue components of human permanent teeth using various decalcifying agents-a comparative study. J Clin Diagn Res 2014;8(9):ZC69-72.

[17] Singh S, Sarkar K. Evaluation of efficacy of various chemicals for decalcification of dental hard tissues-an invitro study. J Orofac Sci 2010;1(1):5-10.

[18] Verdenius HHW, Alma A. A quantitative study of decalcification methods in histology. J Clin Path 1958;11(3):229-36.

[19] Srinivasyaiah A, Nitin P, Hegde U. Comparison of microwave versus conventional decalcification of teeth using three different decalcifying solutions. J Lab Physicians 2016;8(2):106-11.

[20] Nadaf A, Madhura S, Radhika MB, et al. Decalcification: a simpler and better alternative. Journal of Dentistry and Oral Biosciences 2011;2(2):10-3.

[21] Culling CF, Allison RT, Barr WT. Cellular pathology technique. $4^{\text {th }}$ edn. London: Butterworths 1985:408-30.

[22] Savi FM, Brierly GI, Baldwin J, et al. Comparison of different decalcification methods using rat mandibles as a model. J Histochem Cytochem 2017;65(12):705-22.

[23] Prasad P, Donoghue M. A comparative study of various decalcification techniques. Indian J Dent Res 2013;24(3):302-8.

[24] Selving KA. Ultrastructural changes in human dentine exposed to a weak acid. Arch Oral Biol 1968;13(7):71926.

[25] Gruntz S, English V. Expedited bone throughput using bone decalcification. Technical Bulletin for Histology 2011;44(1):1-21. 